\title{
Applying Linear Programming Method in Six Sigma Approach to Developa TruckPlanning Tool - A Case Study
}

\author{
Yanhui Huang ${ }^{1}$, David Ding ${ }^{2}$, \\ ${ }^{I}$ Department of Operations and Management, University of Wisconsin - Stout, Menomonie, WI54751, USA \\ Keyes, P. James ${ }^{3}$, \\ ${ }^{2}$ Department of Operations and Management, University of Wisconsin - Stout, Menomonie, WI54751, USA
}

\begin{abstract}
Six Sigma is a tool for business to achieve continuous improvement. The benefits of implementing Six Sigma projects include cost reduction and productivity improvement. Six Sigma uses the Define, Measure, Analyze, Improve and Control (DMAIC) methodology to solve problems. In this study, the linear programming approach was used in the improve and control phases of a Six Sigma project to find a truck scheduling tool for ABC Transportation Companyto reduce their shipping cost. The key cost variables and their probability distributions were identified in the analyze phase. The study results showed that the new truck scheduling tool would reduce the shipping cost significantly.
\end{abstract}

Keywords: DMAIC, Linear Programming, Process Improvement, Demand Driving

\section{Business Background}

A transportation service provider, $\mathrm{ABC}$ Transportation Company $(\mathrm{ABC})$ normally uses trucks from three resources; trucks owned by $\mathrm{ABC}$, trucks owned by drivers who were partnering with $\mathrm{ABC}$ and trucks rented by $\mathrm{ABC}$ from other transportation service providers. The shipping costs of renting trucks from other transportation service providers were significantly higher than that of $A B C$ owned trucks or drivers that are partnered with the company. If possible, $\mathrm{ABC}$ wanted to use its own trucks and trucks owned by drivers that are partnered with the company. The rental option was only to be used when the first two options could not meet the customers' needs. Table 1 summarizes the capacity, job assignment priority and operation cost of ABC's truck resources. In the past, the majority products were shipped by trucks owned by $\mathrm{ABC}$ and drivers partnered with $\mathrm{ABC}$. With the dramatic increased the shipment needs from customer, $\mathrm{ABC}$ had to ship higher volume to more destinations and more frequently. $\mathrm{ABC}$ was not prepared for the increase in demand and found it had to use more rental trucks from other providers. The purpose of the study was to use Six Sigma methodologies to improve $\mathrm{ABC}$ 's truck capacity planning and scheduling to reduce the shipping cost and increase the company's profits. $\mathrm{ABC}$ used a demand driving scheduling process in which the truck scheduling was based on customer demand. After receiving the customers' order, the operations department combined the orders and assignments into truckloads sorted by destinations. Trucks were assigned based on the total number of truckloads required. If there were not enough company trucks available, ABC rented trucks from contract truck providers. This approach came with the following issues; such as, not enough trucks carrying products to specific destinations and lack of demand forecasting. This study used a Six Sigma approach to reduce the unbalanced scheduling issues, so the capacity of company trucks could be optimized.

\section{Six Sigma and Linear Programming}

Six Sigma is a well-defined process that focuses on problem solving which maximized the return on a company's investments. Six Sigma was developed by Motorola in the 1980's to improve manufacturing processes quality and to enhance customer satisfaction (He, Tang \& Chang, 2010). At the Six Sigma quality level, with a 1.5 standard deviation shift from the process target, the manufacturing process produces 3.4 defective parts per million opportunities (Harry, 1998). Beginning in the 1990's, organizations such as General Electric (GE) and AlliedSignal (Honeywell) used a Six Sigma approach to improve other aspects of operations such as reduced cycle time, increased process yield, and enhanced resources efficiency (Evans \& Lindsay, 2010). The benefit of implementing Six Sigma projects include: Defect and cost reduction, productivity improvements, cycle time reductions, customer relations improvements, and market share increases (Pande, Roland \& Cavanagh, 2000). Hahn \& Hill (1999) reported that Motorola saved \$940 million over three years from Six Sigma projects. AlliedSignal (Honeywell) had an estimated savings of \$1.5 billion for the year 1997 from their Six Sigma initiative and GE received \$1.75 billion for 1998 and \$2.5 billion for 1999 from its \$1 billion investment in Six Sigma improvement projects (Breyfoggle, 2003).

Six Sigma uses Define, Measure, Analyze, Improve and Control (DMAIC) methodology to solve problems (Hahn \& Hill, 1999). The define phase is the first phase of the Six Sigma improvement process. After 
the Six Sigma project plan was approved by the project sponsor, the resources would be in place and the project team could move to the measure phase (Breyfoggle, 2003). A process has to be measured before it can be improved. The measure phase is intended to identify the data that illustrates the state of the current process. The Six Sigma team had to first identify the input and output variables for the process. The team then developed a data collection procedure and sampling plan (Breyfoggle, 2003). The data collection tools included checklists, check sheets and a control chart (Evans \& Lindsay, 2010). The analyze phase was the most important phase in the Six Sigma process (Eckes, 2003). The improvement idea was generated based on the analyzed results. The recommendation for improvement was made in this phase as well. The Six Sigma team used tools such as histograms, Pareto analyses, experimental designs and statistical process control to find root causes for the problem (Evans \& Lindsay, 2010). The improve phase is where the problem solution or corrective action was implemented. The tools used in this phase included experimental designs and hypothesis testing (Evans \& Lindsay, 2010). This phase required multiple attempts until the project goals and objectives were reached. Once the team was able to show that the solution resulted in improvement, they could move on to the control phase (Go Lean Six Sigma, 2013). Researchers recently used linear programming as a mathematical and statistical tool in the Six Sigma analyze and improve phases (Bobek, Imondi, Shott \& Toobaei, 2012). The details about linear programming will be reviewed later in this chapter. The control phase is the last phase in the DMAIC procedure. The objective of this phase is to sustain the achieved improvement in the improve phase. The Six Sigma team needed to create a control plan to ensure the improved process maintained its ability to meet customers' needs (Eckes, 2003). Statistical Process Control is often used in the control phase to monitor the status of process.

Linear programming is the process of finding the optimized outcome for a given set of linear equations related to a specific situation (Moore \& Weatherford, 2001). Many real world problems lend themselves to linear programming modeling or can be approximated by linear models. There was more than one variable combination that resulted in the same object function result (Moore \& Weatherford, 2001). In order to avoid the above situation, researchers often modified the linear model to reach a unique optimized solution. Industry has had a long history of applying linear programming to solve complex problems and find the optimized solutions in production operation and services areas (Balbirer \& Shaw, 1981). Linear programming was used to find optimized solutions for complex situations; researchers recently started to use it as a mathematical and statistical tool in the Six Sigma analyze and improve phases (Bobek et al., 2012). In general, there are two types of truck transportation service providers. They are government owned providers and private providers. ABC would be considered as a private provider. The operational costs of a private truck transportation provider include the following five categories: fuel costs, toll costs, overload fines, late delivery penalties and truck rental costs.

\section{Data Collection}

The shipping cost records were collected for year 2012. The cost records included shipping destination, date shipment requirement received, delivery date, total overload weight and total cost. The consequences associated with overloaded trucks were extra costs including; possible overload fines, extra fuel costs and potential late delivery penalties. However, since there were different random factors such as number of traffic control agencies on duty that might affect the values of extra cost items, it was necessary to understand the probability distribution of the extra cost items. In this study, the researcher determined the probability distribution of the extra cost items based on the frequency of occurrences in the truck record data. The probability distributions for other key cost items such as the probability distributions between overload and late delivery penalty, overload and extra fuel cost will also be determined using the same methodology.

Linear programming was used during the improve phase of the DMAIC process to determine the truck scheduling policy. The variables in this model were the overload weights of truckloads for each shipment. These variables were defined as V1 to Vn, which stands for the total overload weight of each truck. The first set of variable constraints was the overload weights of each truck; the overload weights should not contain negative numbers. The second constraint was the total overload weight volume. This volume will be greater than or equal to the total shipment overload volume. The third constraint was the overload constraint. Even though it was common in the transportation market that trucks were overloaded, each transportation service provider established a maximum overload weight allowance that a truck could be overloaded for safety concerns. ABC had its' own limit for how much weight a truck could handle for different destinations. Based on the above constraint regulations, the following constraint set was established. The constraint set is shown in Figure 1. The objective of this research project was to reduce the shipping cost for ABC Transportation. Based on this, the objective function for linear model was established to minimize the total cost as shown in Figure 2. Pareto analysis was used to identify the key cost items that affected the total truck cost. These variables were programmed into the linear programming model. The input cost items for the Pareto analysis were, extra fuel cost caused by overloaded trucks, overload fines, late delivery penalties, extra cost of rental trucks and extra toll 
costs caused by overload. The cost items of 816 shipping records were summarized. The Pareto chart shown in Figure 3 was created based on the data summary results.

\section{Results of Probability Distributions of Extra Cost Items}

ABC Transportation Company incurred extra costs to use rental trucks. The extra costs rental companies charged varied depending on the market. Based on the frequency count outcome, the probability distribution of extra charge per truck was calculated and summarized in Table 2. A frequency count approach was used to determine the probability distribution between overload weights and overload fines. For example, the 2012 shipping cost records showed that there were 75 trucks that had overload weights between two to three tons. Among these 75 trucks, 15 trucks (20\%) were charged with $\$ 50$ overload fine, 30 trucks (40\%) were charged with $\$ 65$ overload fine and the remaining 30 trucks $(40 \%)$ were charged with $\$ 80$ overload fine. This probability distribution was used in the linear programming model to calculate the overload fines of trucks that had been overloaded by between two to three tons. Table 3 shows the probability distribution between overload weight (ton) and overload fines. The same approach was used to determine the probability distribution between overload weight and extra fuel costs. Table 4 shows the probability distribution between overload weight and extra fuel costs. Table 5 shows the probability distribution between overload weight and late delivery penalties. The probabilities were calculated from frequency count results.

\section{Linear Programming Model}

The key cost items and their probability distributions were used to build the linear programming model. The company's maximum overload weight allowances were also determined. For ABC's company owned trucks, the maximum overload weight allowance is seven tons. The maximum overload weight allowance for rental trucks is 10 tons. The linear constraint set of the linear programming model is shown in Figure 4. The goal of this research was to find a scheduling tool to reduce the shipping cost. In order to achieve this goal, the linear objective function was used to minimize the total shipping cost as shown in figure 5 .

\section{Results of Linear Programming Output}

MS Excel Solver was used to solve the linear programming model. The objective function of the linear model was to minimize the total extra costs. The total extra costs were the summary of extra fuel costs, overload fines, late delivery penalties and extra rental costs. The output of MS Excel solver provided the specified overload value (ton) of each truck. Figure 6 is the analysis output. For this particular week, ABC had to ship 108 tons of overloaded products. The linear programming solution made the following recommendations:

1. The output showed that company trucks V1 through company trucks V10 had finalvalues greater than zero. This indicated that the company had to use 10 company trucks.

2. The overload value of each company truck was the final value from the output.

3. The output showed that the final values of rental trucks V1 through V5 were greaterthan zero, which indicated that $\mathrm{ABC}$ had to use five rental trucks.

4. The overload value of each rental truck was the final value from the output.

5. The total overload amount was 108 tons, which equals the customer requirement.

6. The total cost of the week was $\$ 9,430$ based on this truck capacity planning.

\section{Results of One Month Historical Data Comparison}

A pilot test was conducted by using four weeks of historical data from April 2012 with the linearprogramming approach. The results in Table 6 show that the total truck costs under this newplanning approach would have been $\$ 38,828$, which was $15.2 \%$ less than the actual truck cost $(\$ 45,810)$ of that month. The new approach reduced the truck cost significantly.

\section{Conclusion}

Six Sigma is a tool used to achieve continued improvements. The benefits of implementing Six Sigma projects include; cost reduction and productivity improvement. Six Sigma uses Define, Measure, Analyze, Improve and Control (DMAIC) methodology to solve problems. In this study, a linear programming approach was used during the improve and control phases of a Six Sigma project to develop a truck scheduling tool for ABC Transportation Company. Six Sigma DMAIC approach could reduce an organizations operational cost. It showed that organizations can benefit from successful Six Sigma projects. Linear programming can help an organization determine the optimized capacity planning and resource scheduling. The literature review also showed the challenges and opportunities that transportation providers are facing. A goal of this study was to focus on providing a truck scheduling tool that ABC Transportation Company could use to reduce the shipping cost. This goal was accomplished through Six Sigma DMAIC approach. The key cost variables and their 
probability distributions were identified in the analyze phase. Linear programming was used in the improvement phase to minimize the total cost.

Table 1.Summary of Trucks Used by ABC Company

\begin{tabular}{|l|l|l|l|}
\hline Owner & Number & Job Priority & Operation Cost \\
\hline Trucks owned by ABC & 16 & High & Low \\
\hline Trucks owned by sub-contractors & 24 & Medium & Medium \\
\hline Trucks rented & Unlimited & Low & High \\
\hline
\end{tabular}

Table 2. Probability Distribution of Extra Costs for Rental Truck

\begin{tabular}{|l|l|}
\hline Extra Charge by Rental Company (per Truck) & Probability \\
\hline$\$ 725$ & $168 / 280=60 \%$ \\
$\$ 770$ & $98 / 280=35 \%$ \\
$\$ 840$ & $14 / 280=5 \%$ \\
\hline
\end{tabular}

Table 3. Probability Distribution of Overload Weight vs. Overload Fines

\begin{tabular}{|l|l|l|}
\hline Overload Weight (Ton) & Overload Fine & Probability \\
\hline 1 & $\$ 35$ & $100 \%$ \\
$2-3$ & $\$ 50$ & $20 \%$ \\
& $\$ 65$ & $40 \%$ \\
$4-5$ & $\$ 80$ & $40 \%$ \\
& $\$ 80$ & $20 \%$ \\
& $\$ 130$ & $45 \%$ \\
$6-7$ & $\$ 160$ & $20 \%$ \\
& $\$ 190$ & $15 \%$ \\
& $\$ 130$ & $15 \%$ \\
& $\$ 190$ & $50 \%$ \\
& $\$ 225$ & $25 \%$ \\
& $\$ 260$ & $10 \%$ \\
\hline
\end{tabular}

Table 4.Probability Distribution of Overload Weight vs. Extra Fuel Cost

\begin{tabular}{|l|l|l|}
\hline Overload Weight (Ton) & Extra Fuel Cost & Probability \\
\hline 1 & $\$ 140$ & $45 \%$ \\
2 & $\$ 145$ & $55 \%$ \\
3 & $\$ 145$ & $60 \%$ \\
& $\$ 160$ & $40 \%$ \\
4 & $\$ 170$ & $30 \%$ \\
& $\$ 185$ & $40 \%$ \\
5 & $\$ 193$ & $30 \%$ \\
5 & $\$ 185$ & $40 \%$ \\
& $\$ 200$ & $50 \%$ \\
6 & $\$ 220$ & $10 \%$ \\
& $\$ 200$ & $15 \%$ \\
7 & $\$ 220$ & $20 \%$ \\
& $\$ 225$ & $30 \%$ \\
& $\$ 235$ & $35 \%$ \\
& $\$ 225$ & $35 \%$ \\
& $\$ 235$ & $30 \%$ \\
& $\$ 250$ & $35 \%$ \\
& $\$ 235$ & $20 \%$ \\
& $\$ 250$ & $35 \%$ \\
& $\$ 265$ & $35 \%$ \\
\hline
\end{tabular}

Table 5.Probability Distribution of Overload Weight vs. Late Delivery Penalty

\begin{tabular}{|l|l|l|}
\hline Overload Weight (Ton) & Late Delivery Penalty & Probability \\
\hline $2-3$ & $\$ 35$ & $15 \%$ \\
& $\$ 65$ & $65 \%$ \\
$4-5$ & $\$ 100$ & $20 \%$ \\
& $\$ 35$ & $10 \%$ \\
& $\$ 65$ & $25 \%$ \\
& $\$ 100$ & $55 \%$ \\
$6-7$ & $\$ 130$ & $20 \%$ \\
& $\$ 65$ & $10 \%$ \\
& $\$ 80$ & $10 \%$ \\
& $\$ 130$ & $45 \%$ \\
& $\$ 160$ & $35 \%$ \\
\hline
\end{tabular}


Applying Linear Programming Method in Six Sigma Approach to Develop a Truck Planning Tool -A

Table 6.Actual Cost vs. Linear Programming Output Results for April 2012 Shipment

\begin{tabular}{|l|c|c|}
\hline Cost Item & Actual Cost(April 2012) & Cost Based on Linear Programming Output (April, 2011) \\
\hline Extra Rental Cost & $\$ 16,030$ & $\$ 13,580$ \\
Extra Fuel Cost & $\$ 11,460$ & $\$ 9,720$ \\
Late Delivery Penalty & $\$ 10,080$ & $\$ 8,560$ \\
Overload Fine & $\$ 8,240$ & $\$ 6,970$ \\
Total & $\$ 45,810$ & $\$ 38,828$ \\
\hline
\end{tabular}

$V 1+V 2+V 3+\ldots+V n \geq$ Total Overload Shipment Volume
$V 1 \ldots V n \geq 0$
$V 1 \ldots V n \leq$ Overload Volume Allowed

Figure 1. Linear Programming Variable Constraint Set

$\operatorname{Min}\left[\begin{array}{c}\sum_{i=1}^{n} V i \times \text { Extra Rental Cost }+\sum_{i=1}^{n} V i \times \text { Extra Fuel Cost }+ \\ \sum_{i=1}^{n} V i \times \text { Overload Fine }+\sum_{i=1}^{n} V i \times \text { Late Delivery Fine }\end{array}\right]$

Figure 2. Linear Programming Objective Function

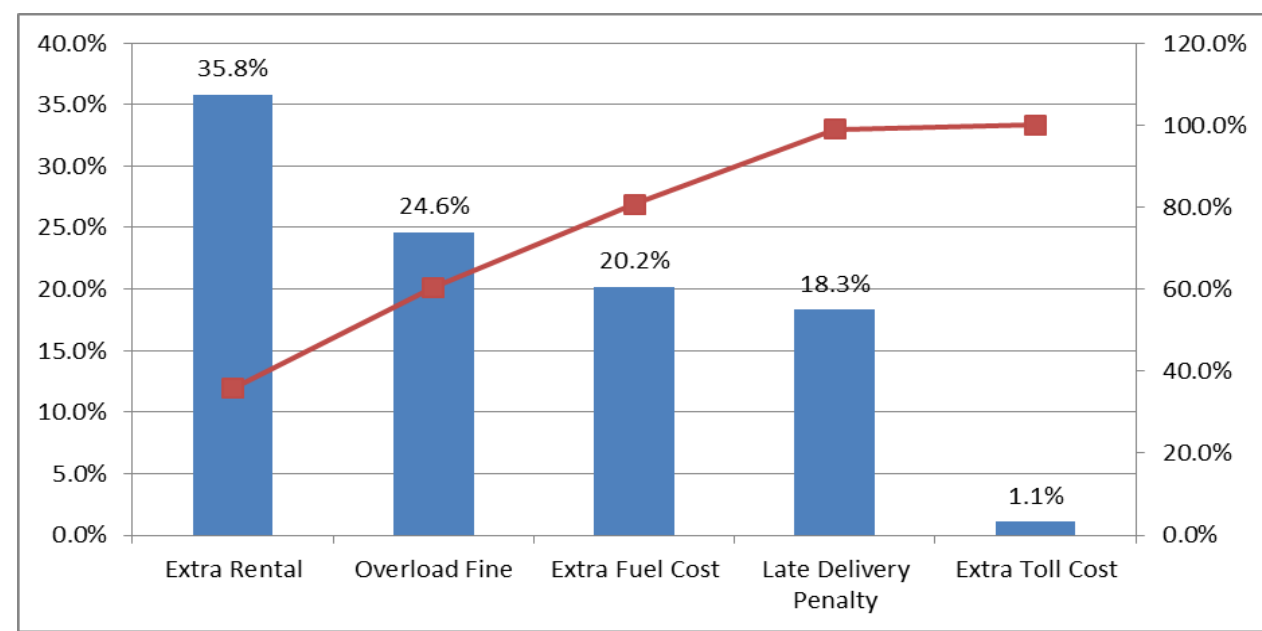

Figure3.Pareto Analysis Results for Key Cost Items

$V 1+V 2+V 3+\ldots+V n \geq$ Total Overload Shipment Volume

$V 1 \ldots V n \geq 0$

Company Owned Truck Overload Weight $\leq 7$

Rental Truck Overload Weight $\leq 10$

Figure 4. Linear Programming Model Variable Constraint Set

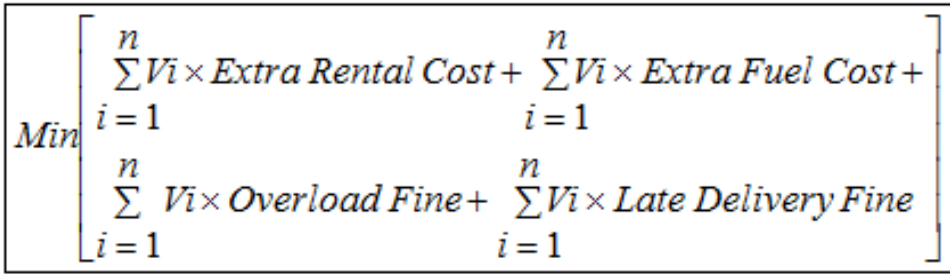

Figure 5. Linear Programming Model Objective Function 


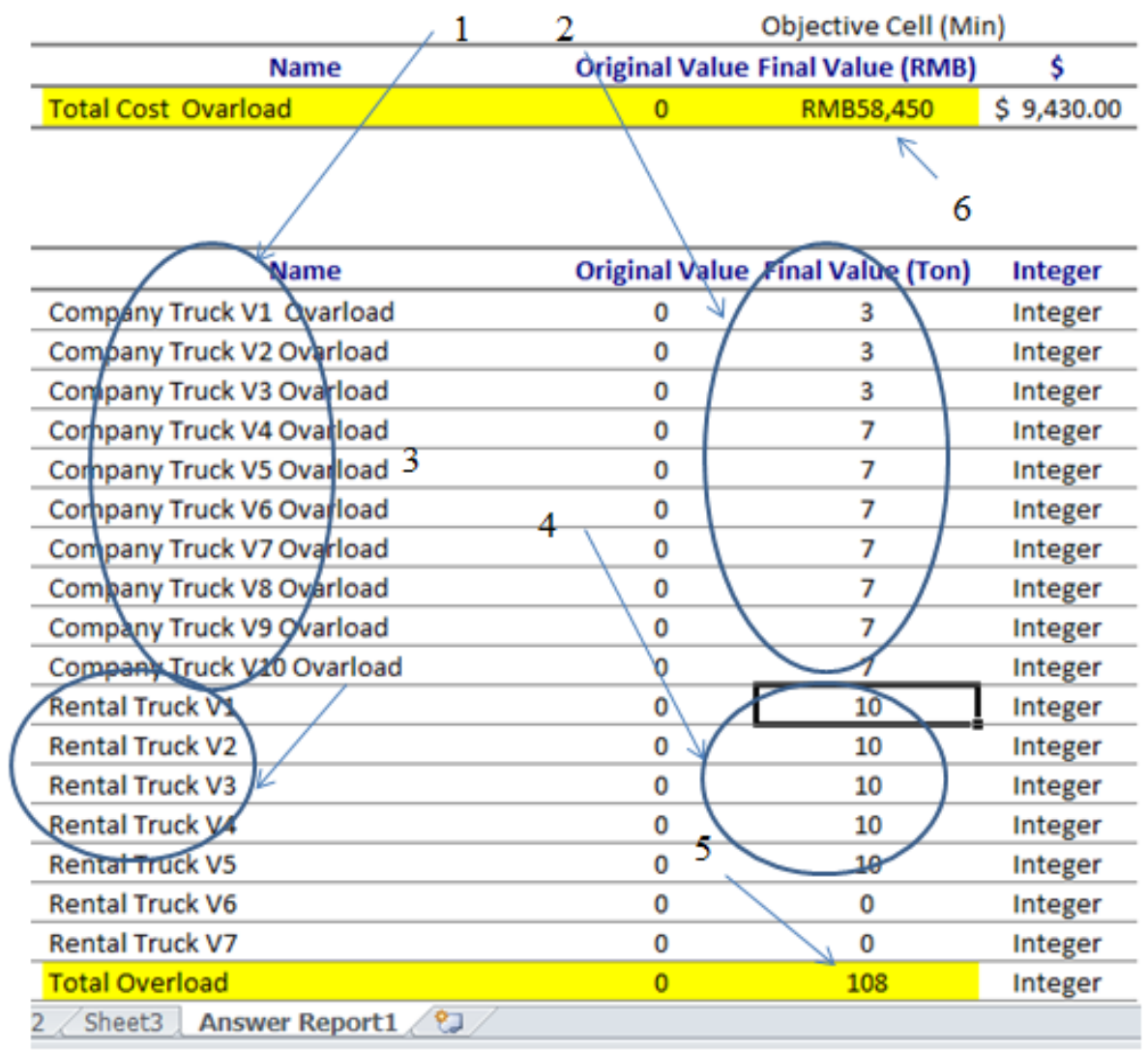

Figure 6. MS Excel Solver Output - Linear Programming Model Solution

\section{References}

[1]. American Society for Quality. (2013). Six Sigma learning resources \& information.Retrieved from http://www.asq.org/learn-aboutquality/six-sigma/overview/overview.html

[2]. Balbirer, S.,\& Shaw, D. (1981). Application of linear programming to bank financial planning. Journal on the Practice of Operations Research, 11(5), 77-83.

[3]. Bobek, A., Imondi, C., Shott, T., \& Toobaei, M. (2012).Heterogeneous project scheduling for optimal Six-Sigma cost reduction using linear programing.Technology Management for Emerging Technologies (PICMET),2012 Proceedings of PICMET '12,3542. Retrieved from http://ieeexplore.ieee.org/xp1/login.jsp?tp=\&arnumber=6304257\&url=http\%3A \%2F\%2Fieexplore.ieee.org\%2Fiel5\%2F6296788\%2F6304012\%2F06304257.pdf\%3Farnumber\%3D6304257

[4]. Breyfoggle III, F. W. (2003). Implementing Six Sigma - Smarter solutions using statistical methods. Hoboken, NJ: John Wiley \& Sons.

[5]. Dickinson, E. (2012). GDP: A brief history. Retrieved from http://www.foreignpolicy.com/ articles/2011/01/02/gdp_a_brief_history\#sthash.1tF4JHfh.dpbs

[6]. Eckes, G. (2003). Six Sigma for everyone.Hoboken, NJ: John Wiley \& Sons, Inc.

[7]. Evans, J., \& Lindsay, W. (2010). Managing for quality and performance excellence.Independence, KY: South-Western Cengage Learning.

[8]. Go Lean Six Sigma. (2013). DMAIC - The 5 phases of lean Six Sigma. Retrieved from

[9]. http://www.goleansixsigma.com/dmaic-five-basic-phases-of-lean-six-sigma/

[10]. He, Y., Tang, X., \& Chang, W. (2010). Technical decomposition approach of critical to quality characteristics for product design for Six Sigma. Quality \& Reliability Engineering International, 26(4), 325-339.

[11]. Harry, M. (1998). Six Sigma: A breakthrough strategy for profitability. Quality Progress, 31(2), 60-64.

[12]. Hahn, H., \& Hill, W. (1999). The impact of six sigma improvement: A glimpse into the future of statistics. The American Statistician, 53(2), 208-215.

[13]. Montgomery, D.C. (2009).Introduction to statisticalquality control. Hoboken, NJ: John Wiley \& Sons.

[14]. Moore, J.,\& Weatherford, L. (2001). Decision modeling with Microsoft Excel. Upper Saddle River, NJ: Prentice Hall.

[15]. Pande, P., Roland, N.,\& Cavanagh, R. (2000). The Six Sigma way: How GE, Motorola, and other top companies are honing their performance. Hoboken, NJ: McGraw-Hill.

[16]. Reytblat, B. (2011). New to Six Sigma. Retrieved from

[17]. http://www.isixsigma.com/new-to-six-sigma/

[18]. Snee, R.D. (1999). Why should statisticians pay attention to Six Sigma? Quality Progress, 32(9), 100. 